Int. J. Dev. Biol. 56: 853-858 (2012)

doi: $10.1387 / \mathrm{ijdb} .120174 \mathrm{mz}$

\title{
OCT4 and the acquisition of oocyte developmental competence during folliculogenesis
}

\author{
MAURIZIO ZUCCOTTI*,1, VALERIA MERICO ${ }^{2}$, MARTINA BELLI ${ }^{2}$, FRANCESCA MULAS ${ }^{3}$, LUCIA SACCHI ${ }^{4}$, \\ BLAZ ZUPAN ${ }^{3,5}$, CARLO ALBERTO REDI ${ }^{2}$, ALESSANDRO PRIGIONE ${ }^{6}$, JAMES ADJAYE ${ }^{6,7}$, RICCARDO BELLAZZI $^{3,4}$, \\ and SILVIA GARAGNA*,2,3,8
}

\begin{abstract}
${ }^{1}$ Dipartimento di Scienze Biomediche, Biotecnologiche e Traslazionali, Universita' degli Studi di Parma, Italy, ${ }^{2}$ Laboratorio di Biologia dello Sviluppo, Dipartimento di Biologia e Biotecnologie 'Lazzaro Spallanzani', Universita 'degli Studi di Pavia, Pavia, Italy, ${ }^{3}$ Centre for Tissue Engineering, University of Pavia, Pavia, Italy, ${ }^{4}$ Dipartimento di Ingegneria Industriale e dell'Informazione, Universita' degli Studi di Pavia, Pavia, Italy, ${ }^{5}$ Faculty of Computer and Information Science, University of Ljubljana, Ljubljana, Slovenia, ${ }^{6}$ Molecular Embryology and Aging Group, Department of Vertebrate Genomics, Max-Planck Institute for Molecular Genetics, Berlin, Germany, ${ }^{7}$ Institute for Stem Cell Research and Regenerative Medicine, Medical Faculty, Heinrich Heiner University, Düsseldorf, Germany and ${ }^{8}$ Centro di Eccellenza in Biologia Applicata, Universita' degli Studi di Pavia, Pavia, Italy.
\end{abstract}

\begin{abstract}
The role that the transcription factor OCT4 plays during oocyte growth is yet unknown. In this review, we summarise the data on its potential role in the acquisition of oocyte developmental competence in the mouse. These studies describe the presence in MII oocytes and 2-cell embryos of an OCT4 transcriptional network that might be part of the molecular signature of maternal origin on which the inner cell mass and the embryonic stem cell-associated pluripotency is assembled and shaped. The Oct4-gene regulatory network thus provides a connection between eggs, early preimplantation embryos and embryonic stem cells.
\end{abstract}

KEY WORDS: OCT4, oocyte, developmental competence, preimplantation development, pluripotency

\section{Introduction}

The key role played by the transcription factor OCT4 in the maintenance of cell pluripotency is well documented for different cell types, such as primordial germ cells (PGCs), spermatogonia, the blastocyst inner cell mass (ICM) and the epiblast. But also in cell types obtained experimentally, such as embryonal carcinoma cells, embryonic stem cells (ESCs) and induced pluripotent stem cells (iPSCs). On the contrary, its presence in the ovary, although reported, remains yet unexplained. Here, we review the data on the presence of OCT4 in the mouse oocyte. Although still scattered, the information obtained thus far indicates a potential role for OCT4 in the acquisition of the oocyte developmental competence and in the establishment of the pluripotency of the ICM.

\section{OCT4 and pluripotency}

During preimplantation development, de novo expression of the OCT4 protein is first observed soon after embryonic genome activation, at the 4-8 cell stage, and plays a key role in the establishment of the trophectoderm (TE) and ICM lineages, since down-regulation of its expression is necessary for TE differentiation (Adjaye et al., 2005; Zernicka-Goetz, 2011). Although heterogeneous levels of expression have been recorded in the different blastomeres throughout preimplantation, its expression level is not predictive of cell lineage patterning (Dietrich et al., 2007). Instead, the analysis of OCT4 kinetic behaviour (i.e., the biological activity of transcription factors in live cells detected by the fluorescence decay after photoactivation assay) demonstrated that blastomeres with lower OCT4 kinetics are more likely to give rise to the pluripotent cells of the ICM (Plachta et al., 2011). Down-regulation of OCT4 in the TE cells is accompanied by the down-regulation in the ICM of CDX2, another key factor in the establishment of the two first cell lineages in the preimplantation embryo (Bruce and Zernicka-Goetz, 2010).

Following implantation, OCT4 is confined to the epiblast and later in development is detected in primordial germ cells (PGCs) (Matsui et al., 1992; Resnik et al., 1992; Goto at al., 1999), in the adult seminiferous epithelium where its presence is confined to type

Abbreviations used in this paper: $\mathrm{ESC}$, embryonic stem cell; ICM, inner cell mass; iPSC, induced pluripotent stem cell; NSN, non surrounded nucleolus PGC, primordial germ cell; SN, surrounded nucleolus, TN, transcriptional network.

\footnotetext{
*Address correspondence to: Maurizio Zuccotti. Dipartimento di Scienze Biomediche, Biotecnologiche eTraslazionali, Universita' degli Studi di Parma, Via Volturno, 39 - 43125, Parma, Italy. e-mail: maurizio.zuccotti@ unipr.it or Silvia Garagna. Laboratorio di Biologia dello Sviluppo, Dipartimento di Biologia e Biotecnologie 'Lazzaro Spallanzani', Universita’ degli Studi di Pavia, Via Ferrata, 9 - 27100, Pavia, Italy. e-mail: silvia.garagna@ unipv.it
}

Final, author-corrected PDF published online: 5 February 2013.

ISSN: Online 1696-3547, Print 0214-6282 
A spermatogonia (for a review see Dym et al., 2009), in the primordial and in growing oocytes (Pesce et al., 1998; Adjaye et al., 1999; Zuccotti et al., 2008; 2009).

\section{OCT4 expression during oocyte growth}

Most of our knowledge on the profile of expression of the Oct4 gene and its protein in the oocyte during folliculogenesis has been obtained adopting a model study in which ovarian mouse oocytes are classified into two main groups depending on their chromatin configuration, as observed when cells are stained with the supravital fluorochrome Hoechst 33342. Following staining, an oocyte is classified as surrounded nucleolus (SN), if it possesses a ring of Hoechst-positive heterochromatin around its nucleolus, or as non surrounded nucleolus (NSN) oocyte, if it lacks of this ring and it shows a more dispersed chromatin(Fig. 1). In 4-6 week-old females, primordial/ primary oocytes with a diameter of 10-20 $\mu \mathrm{m}$ and the following growing phases up to a size of $40 \mu \mathrm{m}$, own an NSN-type of chromatin organisation. Then, at the time of follicle recruitment $(41-50 \mu \mathrm{m})$ about $5 \%$ of oocytes acquire the SN-type of chromatin configuration; a number that increases with growth, reaching a frequency of about $50 \%$ in fully-grown antral oocytes (Zuccotti et al., 1995). An important feature of this model study is that when fully-grown antral SN oocytes are isolated from the ovary, cultured in vitro to the MII stage and inseminated, they complete preimplantation (Zuccotti et al., 1998; 2002) and full-term (Inoue et al., 2008) development; on the contrary, fully-grown NSN antral oocytes arrest development at the 2-cell stage. The presence of these two types of oocytes has been observed in most of the mammalian species studied: in rats (Mandl and Zuckerman, 1952), bovine (Lodde et al., 2008), monkeys (Lefe `vre et al., 1989), pigs (Crozet, 1983) and humans (Parfenov et al., 1989). Only goat (Sui et al., 2005) and equine (Hinrichs and Williams, 1997) oocytes seem to represent exceptions, as their germinal vesicles do not show the SN type of chromatin configuration (for a review see Tan et al., 2009).

In the adult mouse ovary, Oct4transcripts are present throughout folliculogenesis without significant differences between SN and
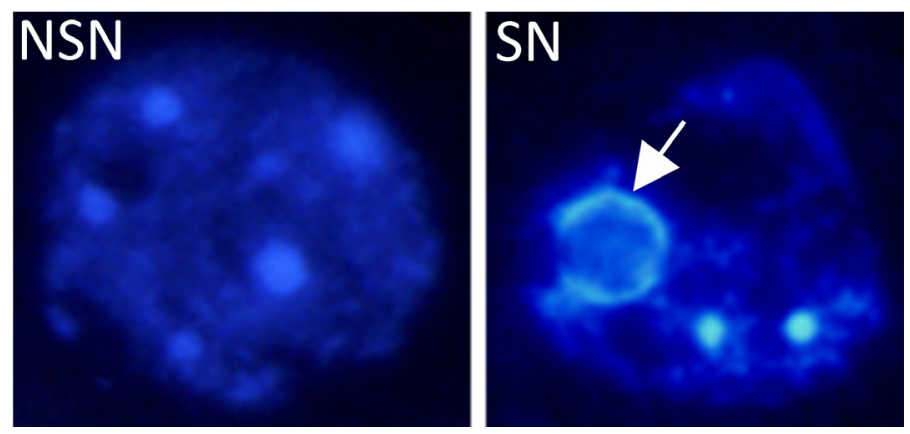

Fig. 1. Chromatin organisation in the nucleus of a non-surrounded nucleolus (NSN) and surrounded nucleolus (SN) oocyte after Hoechst $\mathbf{3 3 3 4 2}$ staining. The arrow indicates the ring of chromatin surrounding the nucleolus in the SN oocyte.

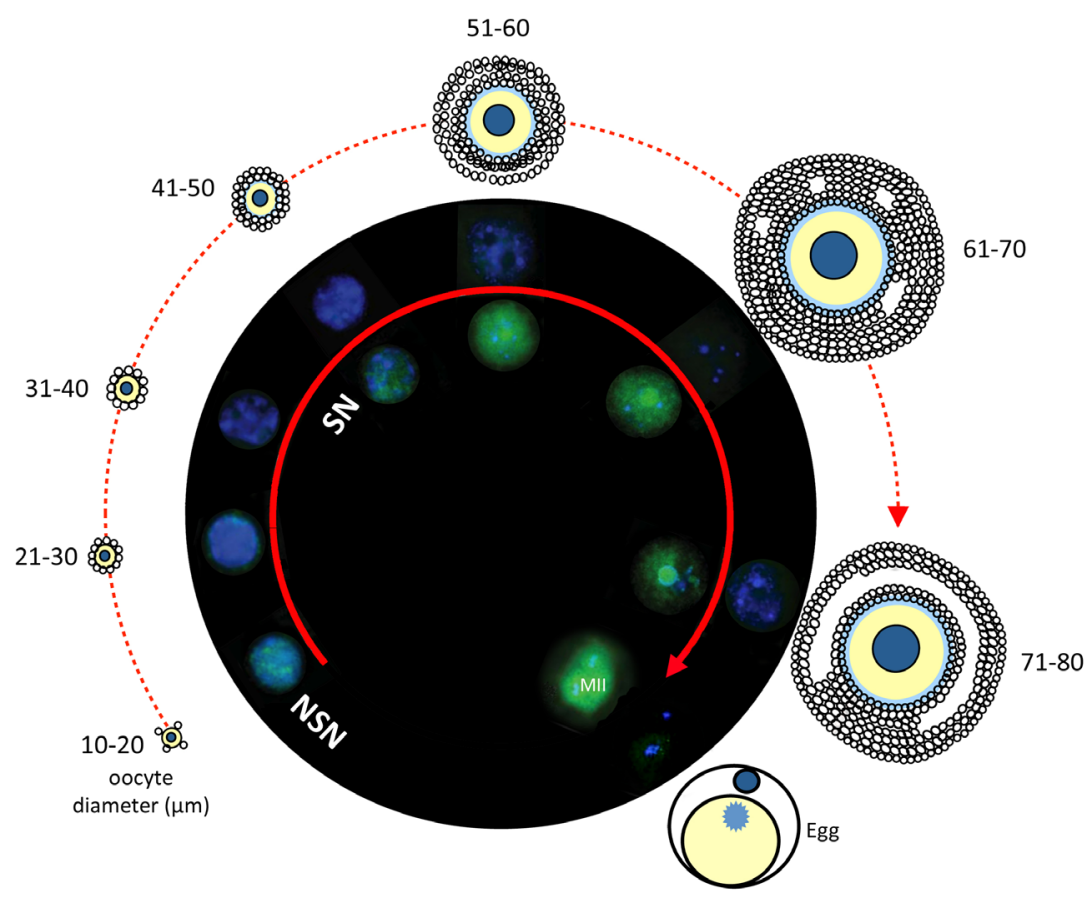

Fig. 2. OCT4 expression in the nucleus of non-surrounded nucleolus (NSN) and surrounded nucleolus (SN) oocytes during folliculogenesis. The OCT4 protein (green ), then it is down-regulated to reappear again later but only in the nucleus of SN oocytes $(41-50 \mu \mathrm{m})$. This profile of expression is maintained throughout oocyte growth and been enlarged for illustrative purposes. Nuclei are counterstained with Hoechst 33342 (blue fluorescence).

NSN oocytes, although the number of transcripts increases from primordial/primary oocytes $(10-20 \mu \mathrm{m})$ to antral oocytes of 61-70 $\mu \mathrm{m}$ and then it decreases in fully-grown and MII oocytes. Instead, the expression pattern of the OCT4 protein during oocyte growth shows a marked difference in the two types of oocytes. OCT4 is expressed in primordial/primary oocytes $(10-20 \mu \mathrm{m})$, and then it is down-regulated in oocytes of 21-40 $\mu \mathrm{m}$ and reappears again, but only in SN oocytes, when follicles are recruited to begin their growth (Pesce et al., 1998; Zuccotti et al., 2009). The profile of expression of this transcription factor remains confined to the SNtype of chromatin configuration also during the following maturation phases up to the fully-grown stage and to the derived developmentally competent MIISN oocyte, whereas it is down-regulated in developmentally incompetent MIINSN oocytes (Zuccotti et al., 2009) (Fig. 2).

As already demonstrated for ESCs (Boyer et al., 2005; Loh et al., 2006; Babaie et al., 2007), the down-regulation of OCT4 in MIINSN oocytes affects, directly or indirectly, the profile of expression of numerous genes, including specific known OCT4-regulated genes. In ESCs the OCT4 transcription factor binds directly to the Nanog locus regulating the expression of a number of pluripotency genes therein, such as Nanog, Stella (also know as Dppa3), Apobec1, Gdf3and Foxj2(Levasseur etal., 2008). Analogously, from the time of follicle recruitment and during the following oocyte growth, upregulation of OCT4 is paralleled by the up-regulation of the STELLA protein in SN oocytes, whereas its down-regulation corresponds to STELLA down-regulation in ovarian NSN and in their derived 
MIINSN oocytes (Zuccotti et al., 2009). Furthermore, as observed in ESCs, the expression of Foxj2 in developmentally incompetent MIINSN oocytes is up-regulated in the absence of OCT4; whereas Foxj2 is down-regulated in the presence of OCT4 in developmentally competent MIISN oocytes (Zuccotti et al., 2009).

Both STELLAand Foxj2 play an important role in preimplantation development. STELLA, the best known, is a maternal-effect factor required at the 1-cell stage to protect against demethylation of the maternal genome and of some paternal imprinted genes (Nakamura et al., 2007); its lack of expression leads to a developmental arrest mainly at the 2-cell stage (Payer et al., 2003). Furthermore, Foxj2 up-regulation leads to a developmental block at the 2-cell stage (Martin-de-Lara et al., 2008).

Although a direct function of OCT4 on the Nanog locus in oocytes as not been yet proved, the observed behaviour analogies of OCT4 in ESCs and oocytes indicate the centrality of this interaction in the acquisition of the oocyte developmental competence and suggest, in this respect, the need for further investigations.

\section{Effects of the down-regulation of OCT4 on the oocyte transcriptome}

Whilst the expression of other maternal-effect genes (i.e., Npm2, Zar1, Smarca4 and Prei3) does not appear to be affected, as they are equally expressed in MIISN and MIINSN oocytes (Zuccotti et al., 2008), the down-regulation of OCT4 in MIINSN oocytes affects a large number of other genes. Microarray-based comparison of the whole transcriptome profile of developmentally incompetent MII ${ }^{\text {NSN }}$ vs. competent $\mathrm{MIISN}$ oocytes brought to light a group of 380 regulated genes, of which 303 up-regulated and 77 down-regulated in MIINSN oocytes. Twenty-five of the 380 regulated genes are known to be regulated by OCT4, 18 of which (up-regulated) are assigned to apoptosis or mitochondrial dysfunction (Zuccotti et al., 2008), indicating that OCT4 down-regulation activates biological pathways that are detrimental to the cell. Furthermore, in keeping with this approach, comparison between MIINSN vs. MIIctrl ovulated oocytes and their derived 2-cel|NSN vs. 2-cel|ctrl, identified an expanded Oct4 transcriptional network made of 197 genes, comprising 102 genes expressed exclusively in MII oocytes, 15 genes solely in 2-cell embryos and 80 genes in both MII oocytes and 2-cell embryos (Fig. 3) (Zuccotti et al., 2011). Gene onthology enrichment analysis of the function of these 197 genes assigned them to several major biological processes, including pluripotency, chromatin organisation, apoptosis, subcortical maternal complex, transcription factorscancer, translation-cancer, oxidative phosphorylation, porphyrin metabolism, anion exchange, TGF- $\beta$ signalling, copper distribution, regulation of transcription, protein phosphorilation, cell cycle, protein assembly and signal transduction (Fig. 4).

The group of 80 genes that operates in MII oocytes and includes known OCT4-regulated genes (from now on named Oct4 transcriptional network, Oct4-TN), survives the massive transcriptional erasure that occurs following fertilisation (Li et al., 2010) and is expressed in 2-cell embryos. Most genes of the Oct4-TN are expressed in cancer cells and 37 are known partners of the Oct4 transcriptome in ESCs (Boyer et al., 2005; Loh et al., 2006; Babaie et al., 2007) (Fig. 5). Interestingly, the majority of these genes are down-regulated in MIIctrl oocytes, whereas after fertilisation, the same genes result up-regulated in 2-cellctrl embryos, an expression behaviour that is confirmed by the immunoanalysis of the proteins of two of these genes (DNMT3L and RSP20; Zuccotti et al., 2011).

Among the biological processes that emerge in the Oct4-TN in MIl oocytes, two are worth a particular mention for the role that they

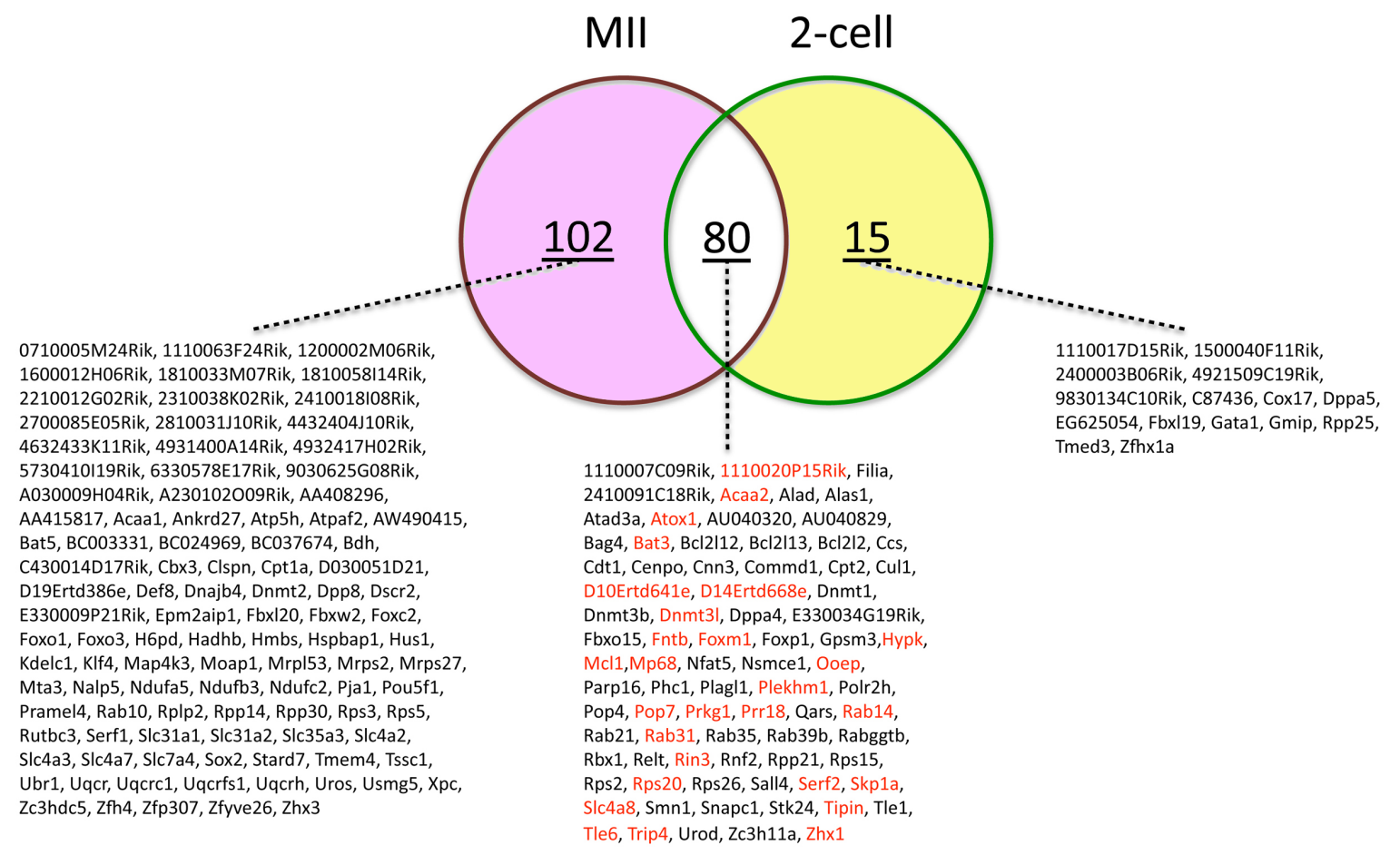

Fig. 3. Venn diagram showing the Oct4-transcriptional network genes that are expressed in MIl oocytes or in 2-cell embryos and those that are present at both developmental stages. In red, OCT4-regulated genes. 


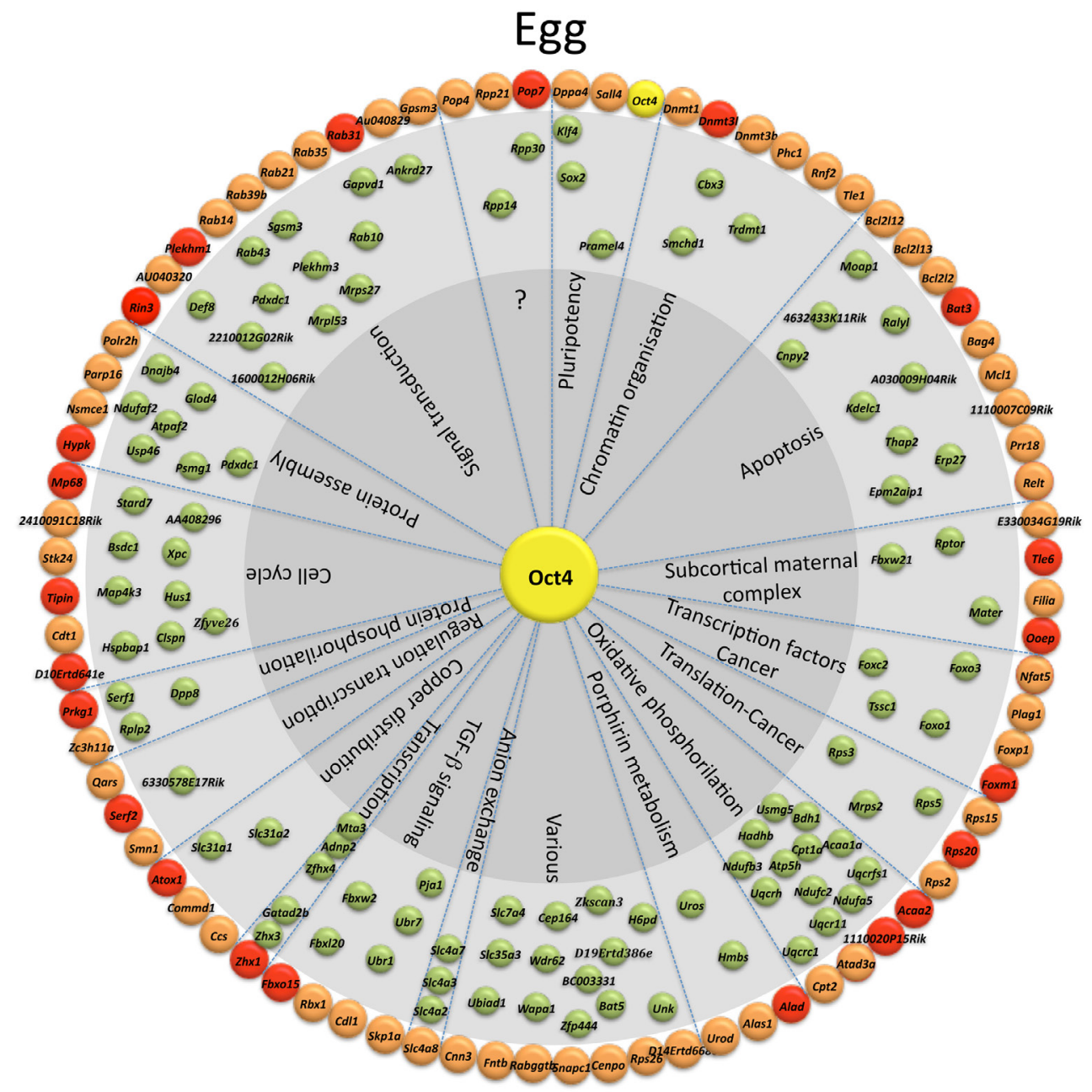

Fig. 4 (above). Distribution of the MII oocyte Oct4-transcriptional network genes in nineteen main biological processes. Green, gene transcripts detected only in MIl oocytes; orange and red, genes of the Oct4-TN expressed in both eggs and 2-cell embryos; red, known OCT4-regulated genes.
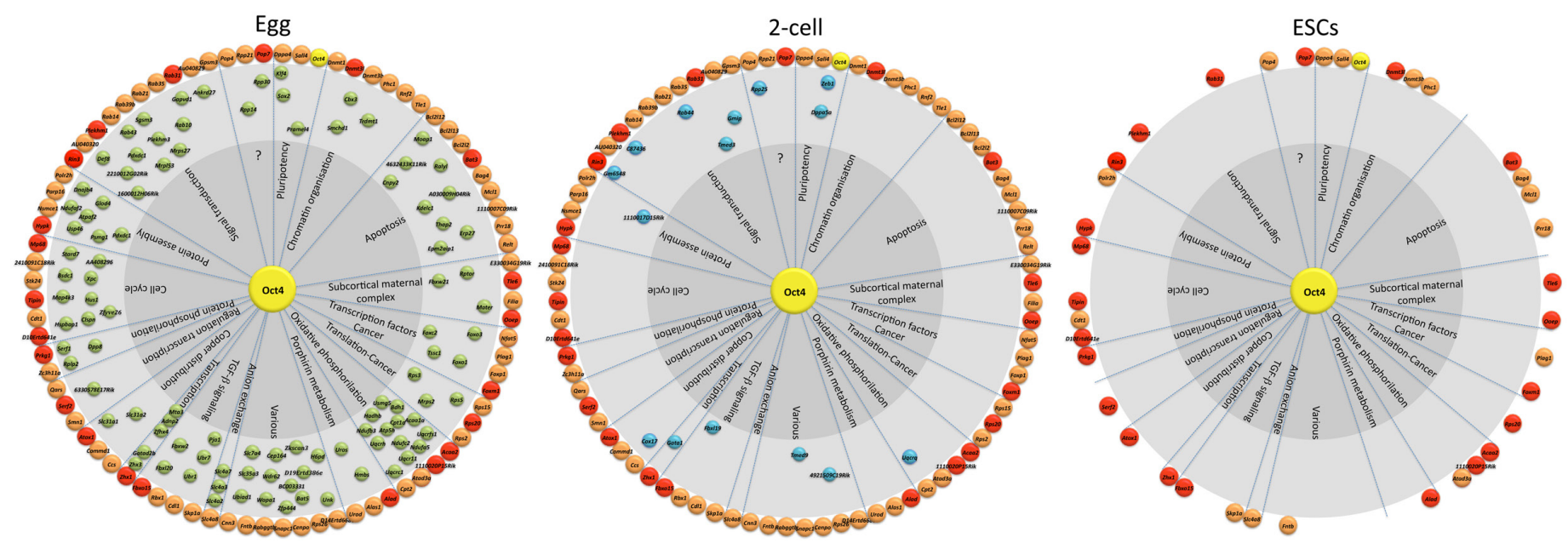

Fig. 5. Oct4-transcriptional network (Oct4-TN) expression in eggs, 2-cell embryos and embryonic stem cells. Green, gene transcripts detected only in MIl oocytes; orange and red, genes of the Oct4-TN expressed in both eggs and 2-cell embryos; red, known OCT4-regulated genes; blue, genes expressed only in 2-cell embryos. 


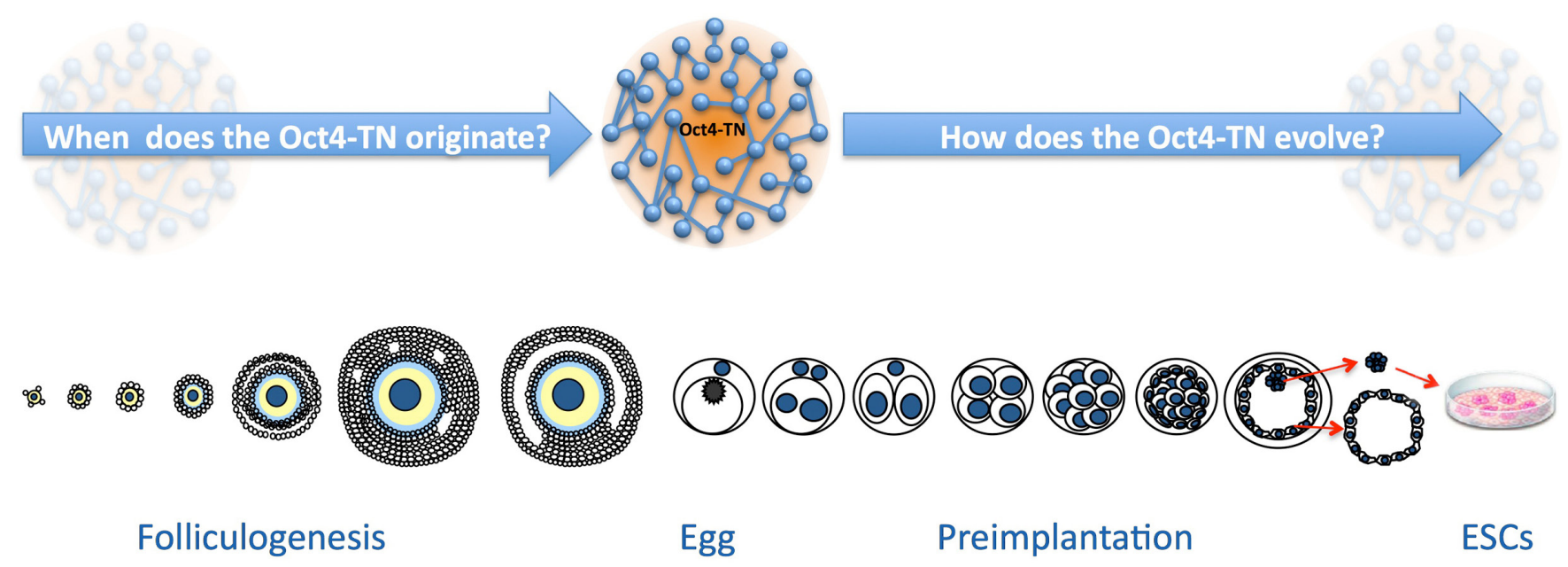

Fig. 6. Future studies of the expression profile of the Oct4-transcriptional network (Oct4-TN) during folliculogenesis, aimed at understanding when it originates during folliculogenesis, and at describing the precise changes occurring during the transition from zygote to blastocyst and in the embryonic stem cells (ESCs).

play in developmental processes. The proteins of the maternaleffect genes Mater, Tle6, Ooep and Filia belong to the subcortical maternal complex (Fig. 4) (Li et al., 2008), they are located in the subcortex of MII oocytes and required for zygotes to progress beyond the first embryonic cell divisions of preimplantation mouse development. During cleavage, these proteins are excluded from regions of blastomere-blastomere contact and segregate to the outer cells of the morula and blastocyst embryo during the TE/ ICM differentiation. Another group of 'pluripotency'-associated genes includes Dppa4, Sall4, KIf4 and Sox2, the latter two being well-known OCT4 companions in the maintenance of self-renewal and pluripotency in ESCs and their over-expression together with that of Oct4 and c-Myc induces dedifferentiation of terminally differentiated somatic cells (e.g., fibroblasts) and the formation of iPSCs (Yamanaka, 2007).

\section{Further perspectives and experiments}

Even though the results of these studies do not provide a definitive answer as to the precise function played by OCT4 in folliculogenesis, they reveal a number of evidences of a correlation between OCT4 and the oocyte developmental competence and of a relationship between this transcription factor and a number of genes that are present also in the OCT4 gene regulatory network operative in ESCs. These data indicate that Oct4-TN might be part of the molecular signature of maternal origin on which the ESCs molecular identity is assembled and shaped, thus providing a connection between eggs, early preimplantation embryos and ESCs.

Future experiments ought now to describe the transcriptional and translational behaviour of the Oct4-TN genes during oocyte growth and preimplantation development, up to the implanting blastocyst, when differentiation of the TE and ICM cell lines occurs (Fig. 6). Also, inactivation of the Oct4 gene expression (e.g., by RNAi or morpholino injection into the oocyte) at the time of follicle recruitment, would give a more precise picture of the molecular function played by OCT4 within this developmental context.

\section{Acknowledgments}

We thank the following organisations for supporting this research:
UNIPV-Regione Lombardia, FondazioneAlma Mater Ticinensis, Fondazione I.R.C.C.S. Policlinico San Matteo, Fondazione Cariplo grant (2008-2006) "Bioinformatics for Tissue Engineering: Creation of an International Research Group" and 'Bando Giovani Ricercatori 2007'.

\section{References}

ADJAYE, J., BOLTON, V., MONK, M. (1999). Developmental expression of specific genes detected in high-quality cDNA libraries from single human preimplantation embryos. Gene 237: 373-383.

ADJAYE, J., HUNTRISS, J., HERWIG, R., BENKAHLA, A., BRINK, T.C., WIERLING, C., HULTSCHIG, C., GROTH, D., YASPO, M.L., PICTON, H.M., et al., (2005). Primary differentiation in the human blastocyst: comparative molecular portraits of inner cell mass and trophectoderm cells. Stem Cells 23: 1514-1525.

BABAIE, Y., HERWIG, R., GREBER, B., BRINK, T., WRUCK, W., GROTH, D., LEHRACH, H., BURDON, T., ADJAYE, J. (2007). Analysis of OCT4-dependent transcriptional networks regulating self-renewal and pluripotency in human embryonic stem cells. Stem Cells 25: 500-510.

BOYER, L., LEE, T., COLE, M., JOHNSTONE, S., LEVINE, S., ZUCKER, J., GUENTHER, M., KUMAR, R., MURRAY, H., JENNER, R., et al., (2005). Core transcriptional regulatory circuitry in human embryonic stem cells. Cell 122: 947-956.

BRUCE, AW., ZERNICKA-GOETZ M. (2010). Developmental control of the early mammalian embryo: competition among heterogeneous cells that biases cell fate. Curr Opin Genet Dev 20: 485-491.

CROZET, N. (1983). Effects of actinomycin D and cycloheximide on the nucleolar ultrastructure of porcine oocytes. Biol Cell 48: 25-29.

DIETRICH, J.E., HIIRAGI, T. (2007). Stochastic patterning in the mouse pre-implantation embryo. Development 134: 4219-4231.

DYM, M., HE, Z., JIANG, J., PANT, D., KOKKINAKI, M. (2009). Spermatogonial stem cells: unlimited potential. Reprod Fertil Dev 21: 15-21.

GOTO, T., ADJAYE, J., RODECK, C.H., MONK, M. (1999). Identification of genes expressed in human primordial germ cells at the time of entry of the female germ line into meiosis. Mol Hum Reprod 5: 851-860.

HINRICHS, K., WILLIAMS, K. (1997). Relationships among oocyte-cumulus morphology, follicular atresia, initial chromatin configuration, and oocyte meiotic competence in the horse. Biol Reprod 57: 377-384.

INOUE, A., NAKAJIMA, R., NAGATA, M., AOKI, F. (2008). Contribution of the oocyte nucleus and cytoplasm to the determination of meiotic and developmental competence in mice. Hum Reprod 23: 1377-1384.

LEFÈVRE, B., GOUGEON, A., NOMÉ, F., TESTART, J. (1989). In vivo changes in oocyte germinal vesicle related to follicular quality and size at mid-follicular phase during stimulated cycles in the cynomolgus monkey. Reprod Nutr Dev29:523-531. 
LEVASSEUR, D., WANG, J., DORSCHNER, M., STAMATOYANNOPOULOS, J., ORKIN, S. (2008). Oct4 dependence of chromatin structure within the extended Nanog locus in ES cells. Genes Dev 22: 575-580.

LI, L., BAIBAKOV, B., DEAN, J. (2008). A subcortical maternal complex essential for preimplantation mouse embryogenesis. Dev Cell 15: 416-425.

LI, L., ZHENG, P., DEAN, J. (2010). Maternal control of early mouse development. Development 137: 859-870.

LODDE, V., MODINA, S., MADDOX-HYTTEL, P., FRANCIOSI, F., LAURIA, A., LUCIANO, A.M. (2008). Oocyte morphology and transcriptional silencing in relation to chromatin remodeling during the final phases of bovine oocyte growth. $\mathrm{Mol}$ Reprod Dev 75: 915-924.

LOH, Y., WU, Q., CHEW, J., VEGA, V., ZHANG, W., CHEN, X., BOURQUE, G., GEORGE, J., LEONG, B., LIU, J., et al., (2006). The Oct4 and Nanog transcription network regulates pluripotency in mouse embryonic stem cells. Nat Genet 38: $431-440$.

MANDL, A., ZUCKERMAN, S. (1952). The growth of the oocyte and follicle in the adult rat. J Endocrinol 8: 126-132.

MARTÍN-DE-LARA, F., SÁNCHEZ-APARICIO, P., ARIAS DE LA FUENTE, C., REYCAMPOS, J. (2008). Biological effects of FoxJ2 over-expression. Transgenic Res 17: 1131-1141.

MATSUI, Y., ZSEBO, K., HOGAN, B. (1992). Derivation of pluripotential embryonic stem cells from murine primordial germ cells in culture. Cell 70: 841-847.

NAKAMURA, T., ARAI, Y., UMEHARA, H., MASUHARA, M., KIMURA, T., TANIGUCHI, H., SEKIMOTO, T., IKAWA, M., YONEDA, Y., OKABE, M., et al., (2007). PGC7/Stella protects against DNA demethylation in early embryogenesis. Nat Cell Biol 9: 64-71.

PARFENOV, V., POTCHUKALINA, G., DUDINA, L., KOSTYUCHEK, D., GRUZOVA, M. (1989). Human antral follicles: oocyte nucleus and the karyosphere formation (electron microscopic and autoradiographic data). Gamete Res 22: 219-231.

PAYER, B., SAITOU, M., BARTON, S.C., THRESHER, R., DIXON, J.P., ZAHN, D., COLLEDGE, W.H., CARLTON, M.B., NAKANO, T., SURANI, M.A. (2003). Stella is a maternal effect gene required for normal early development in mice. Curr Biol 13: 2110-2117

PESCE, M., WANG, X., WOLGEMUTH, D., SCHÖLER, H. (1998). Differential eXpression of the Oct-4 transcription factor during mouse germ cell differentiation. Mech Dev 71: 89-98.
PLACHTA, N., BOLLENBACH, T., PEASE, S., FRASER, S.E., PANTAZIS, P. (2011) Oct4 kinetics predict cell lineage patterning in the early mammalian embryo. Nat Cell Biol 13: 117-123.

RESNICK, J., BIXLER, L., CHENG, L., DONOVAN, P. (1992). Long-term proliferation of mouse primordial germ cells in culture. Nature 359: 550-551.

SUI, H., LIU, Y., MIAO, D., YUAN, J., QIAO, T., LUO, M., TAN, J. (2005). Configurations of germinal vesicle (GV) chromatin in the goat differ from those of other species. Mol Reprod Dev 71: 227-236.

TAN, J., WANG, H., SUN, X., LIU, Y., SUI, H., ZHANG, J. (2009). Chromatin configurations in the germinal vesicle of mammalian oocytes. Mol Hum Reprod 15: 1-9.

YAMANAKA, S. (2007). Strategies and new developments in the generation of patient-specific pluripotent stem cells. Cell Stem Cell 1: 39-49.

ZERNICKA-GOETZ, M. (2011). Proclaiming fate in the early mouse embryo. Nat Cell Biol 13: 112-114.

ZUCCOTTI, M., MERICO, V., BELLONE, M., MULAS, F., SACCHI, L., REBUZZINI, P., PRIGIONE, A., REDI, C.A., BELLAZZI, R., ADJAYE, J., et al., (2011). Gatekeeper of pluripotency: A common Oct4 transcriptional network operates in mouse eggs and embryonic stem cells. BMC Genomics 12: 345.

ZUCCOTTI, M., GIORGI ROSSI, P., MARTINEZ, A., GARAGNA, S., FORABOSCO, A., REDI, C. (1998). Meiotic and developmental competence of mouse antral oocytes. Biol Reprod 58: 700-704.

ZUCCOTTI, M., MERICO, V., SACCHI, L., BELLONE, M., BRINK, T., BELLAZZI, R. STEFANELLI, M., REDI, C., GARAGNA, S., ADJAYE, J. (2008). Maternal Oct-4 is a potential key regulator of the developmental competence of mouse oocytes. BMC Dev Biol 8: 97.

ZUCCOTTI, M., MERICO, V., SACCHI, L., BELLONE, M., BRINK, T., STEFANELLI, M., REDI, C., BELLAZZI, R., ADJAYE, J., GARAGNA, S. (2009). Oct-4 regulates the expression of Stella and Foxj2 at the Nanog locus: implications for the developmental competence of mouse oocytes. Hum Reprod. 9: 2225-2237.

ZUCCOTTI, M., PICCINELLI, A., GIORGI ROSSI, P., GARAGNA, S., REDI, C. (1995). Chromatin organization during mouse oocyte growth. Mol Reprod Dev 41:479-485

ZUCCOTTI, M., PONCE, R., BOIANI, M., GUIZZARDI, S., GOVONI, P., SCANDROGLIO, R., GARAGNA, S., REDI, C. (2002). The analysis of chromatin organisation allows selection of mouse antral oocytes competent for development to blastocyst. Zygote 10: 73-78. 


\section{Further Related Reading, published previously in the Int. J. Dev. Biol.}

Reprogramming cell fate: a scientific journey from viral enhancers to the master gene regulator Oct4 - an interview with Hans R. Schöler .

Michele Boiani

Int. J. Dev. Biol. (2010) 54: 1685-1695.

Enhancing somatic nuclear reprogramming by Oct4 gain-of-function in cloned mouse embryos.

Martin J. Pfeiffer, Sebastian T. Balbach, Telma C. Esteves, Nicola Crosetto and Michele Boiani. Int. J. Dev. Biol. (2010) 54: 1649-1657.

Exploring refined conditions for reprogramming cells by recombinant Oct4 protein. Marc Thier, Bernhard Münst and Frank Edenhofer.

Int. J. Dev. Biol. (2010) 54: 1713-1721.

Analysis of SOX2 expression in developing human testis and germ cell neoplasia. Si B. Sonne, Rebecca M. Perrett, John E. Nielsen, Melissa A. Baxter, David M. Kristensen, Henrik Leffers, Neil A. Hanley and Ewa Rajpert-De-Meyts.

Int. J. Dev. Biol. (2010) 54: 755-760.

Expression of NANOG and NANOGP8 in a variety of undifferentiated and differentiated human cells.

Sakthikumar Ambady, Christopher Malcuit, Olga Kashpur, Denis Kole, William F. Holmes, Emmett Hedblom, Raymond L. Page and Tanja Dominko.

Int. J. Dev. Biol. (2010) 54: 1743-1754.

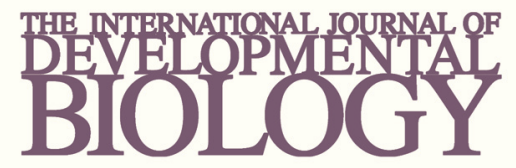

Volume 54 Nos. $6 / 7$
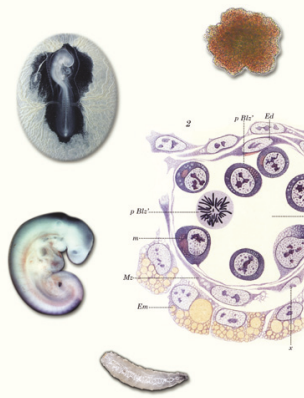

(2.) (3)

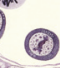

(a)

(c)

Special Issue
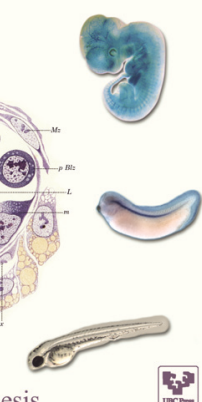

5 yr ISI Impact Factor $(2011)=2.959$

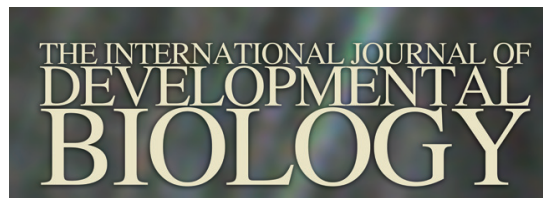

Volume 56 Nos. 1/2/3

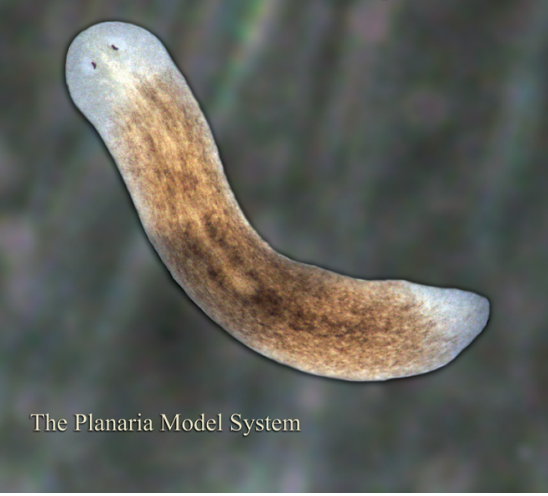

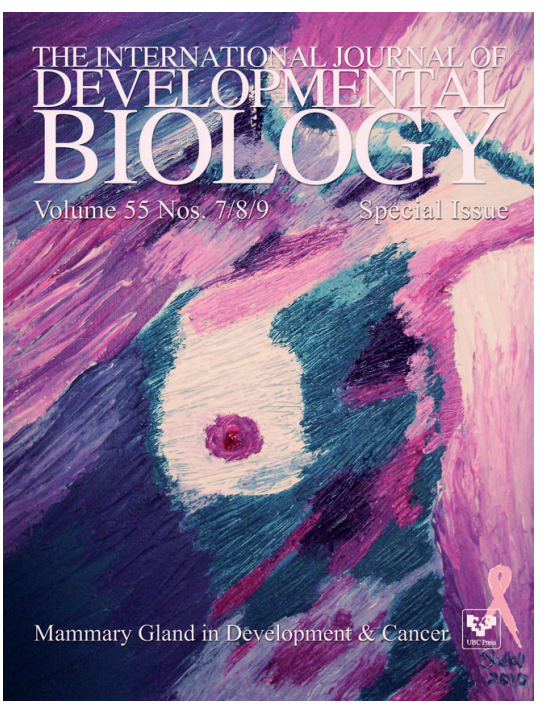

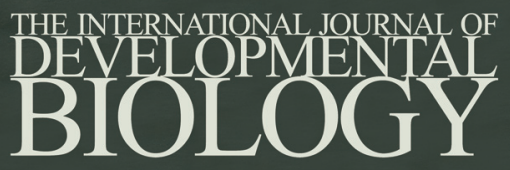

Volume 55 Nos. $4 / 5$

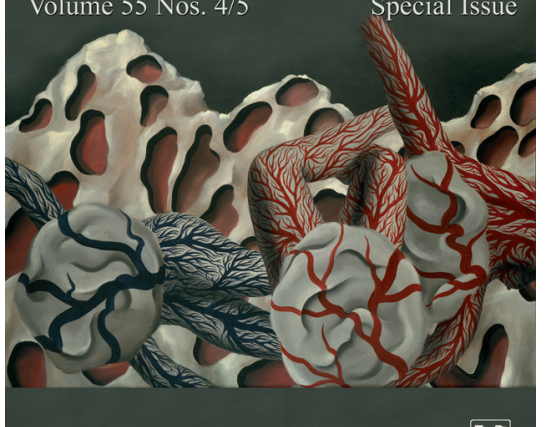

Angiogenesis in Development \& Cance 